\title{
Development of quality improvement matrix: An integrated tools for quality improvement
}

\author{
Katon Muhammad ${ }^{1, *}$ and Putu Dana Karningsih ${ }^{1}$ \\ ${ }^{1}$ Department of Industrial Engineering, Institut Teknologi Sepuluh Nopember, 60111 Surabaya, \\ Indonesia
}

\begin{abstract}
Continuous quality improvement is essential to ensure the competitiveness of manufacturing industries. Design of Experiments, Statistical Process Control and Failure Mode and Effect Analysis are common tools for improving quality. This study proposes a new tool that could encompass quality improvement steps comprehensively, namely Quality Improvement Matrix. This tool integrates several techniques which are House of Quality, Failure Mode and Effect Analysis (FMEA) and Root Cause Analysis. Quality Improvement Matrix covers identification of defects and its root causes, measuring the magnitude of defects (source of defects), formulating alternatives of solutions for reducing root cause of defects and selecting effective solutions to be implemented. Quality Improvement Matrix is developed by following a similar approach as House of Risk. Thus, it also consists of two matrixes that represent two major stages. The first stage is the identification and prioritizing root causes of defect. Then, the second stage is formulating and selecting solutions for improvements.
\end{abstract}

\section{Introduction}

The definition of quality according to [7] is conformity of which are related to two aspects they are quality of design and quality of conformance. Quality of design relates to size, appearance, and performance. As for the quality of conformance related to the suitability of the product to the specifications required by the design. The more modern definition of quality is inversely proportional to variability, where if a product produced has a high variability reflects the low quality of the resulting product vice versa. The process of improving quality of a product is very important and also fundamental in a process of product improvement in the manufacturing industry.

The quality improvement process often uses Define Measure Improve Control (DMAIC) procedure. DMAIC is a structured procedure for problem-solving used for quality improvement processes [7]. Define phase is the stage for identifying existing defects. In Define phase, we can use check sheet tools, Pareto diagrams and some similar tools to identify defects. Furthermore, Measure phase aims to evaluate and understand the current state of the process. In this phase, data about existing quality is collected. In this

\footnotetext{
* Corresponding author: katon.muhammad@gmail.com
} 
phase, we can use some tools to be able to measure the quality or the process being observed such as using the control chart and histogram. Analyze phase aims to determine the causal relationships in the process and to determine the various sources of variability, in other words in this phase analyze will determine the potential causes of a defect and quality problems that occur. In this phase, some tools on can be used such as Failure Mode and Effect Analysis, Root Cause Analysis (RCA) and cause and effect diagram. At the fivestage, Improvement phase search for a solution to improve the existing process to reduce defect of the product. Some tools can be used in this phase, for example, redesign process to improve workflow by using a flow chart or use design of experiment to improve the quality problem.

According to [4] there are several tools that are often used to improve product quality in manufacturing industries such as Design of Experiment (DOE), Statistical Process Control (SPC) and Failure Mode and Effect Analysis (FMEA) can make good quality improvements, but their use should still be integrated with other tools to cover ranging from defect identification, Measure, Analysis and finding the root cause of the defect to making recommendations for improvements to overcome the existing defect. There are several existing research on quality improvement that integrates several tools. Research of [3] integrates FMEA and Pareto for improving quality of manufacturing processes. Research of [1] combines FMEA with SPC while [5] also combines with SIPOC. Research of [8] combines Failure Mode and Effect Analysis (FMEA) and House of Quality (HOQ) but for managing risk in the supply chain. The tool is called House of Risk (HOR). HOR aims to identify, analyze, measure and mitigate the risks that will potentially arise by designing an effective handling strategy. This method consists of two matrices and it can cover from identification, analysis, measuring to mitigate a potential risk. By following the same logic, this research aims to develop a tool for improving quality by also integrating FMEA and HOQ as well as RCA (5 why's), the proposed tool is called Quality Improvement Matrix (QIM). QIM could encompasses from identification of defects and their root causes until prioritizing improvement recommendation for improving quality in production processes. Thus, QIM could support industry in managing quality by providing a more comprehensive and simple tool as it is only consists of two matrices.

\section{Literatur Review}

\subsection{House of Quality (HOQ)}

House of Quality (HOQ) is one of the elements of the Quality Function Deployment method (QFD). House of Quality uses a planning matrix to link customer needs with methods used by manufacturers to meet customer needs. House of Quality considers the impact of customer needs "what" the technical characteristics of "how" and the quality of existing products on the market today. Competitiveness matrix has been added to HOQ to better shows the various factors that influence the design and evaluation of technology [6]. According to [10] results from HOQ are used to prioritize customer needs and identify deficiencies in a comparable technology. This information can then be used for selection, compilation, adjustment, modification, and optimization of the original plan, so as to enable customers to be more satisfied and improve their competitiveness.

\subsection{Failure Mode and Effect Analysis (FMEA)}

Failure Mode and Effect Analysis (FMEA) is a tool used to identify known failures or potential failures that are subsequently applied to enhance the reliability and security of 
complex systems. On the other hand, FMEA is a technique that provides information for risk management decisions. It is used to investigate the causes and effects of defects that are further detected in order to reduce the possibility of dislocation [2]. This tool incorporates technology and draws from one to the next in identifying a possible failure method of a process or product to be further developed to address its responses [9].

\subsection{House of Risk (HOR)}

House of risk is a method that aims to identify, analyze, measure and mitigate potential risks by designing a strategy to reduce or eliminate the source of risk agents. This method is a modification and integration of two methods namely House of Quality and also Failure Mode and Effect Analysis. The FMEA method is used to identify the potential failure of a product and perform the action used to eliminate or minimize the risk of failure and this method is also used to quantify the risk by quantitatively exploring the Risk Priority Number (RPN) calculation. While the concept of HOQ used in this method is to design the strategy so that this concept can be used to design the mitigation strategy to reduce risk and identify risk. This HOR method consists of two matrices. The first matrix is used to determine which risk agents should be prioritized for precautions, while the second matrix is used to design the mitigation strategy for priority risk agents to be addressed [8].

\section{Development of Quality Improvement Matrix}

The development of this new tool for quality improvement follows the development of the House of Risk (HOR) tool that incorporates House of Quality (HOQ) and Failure Mode and Effect Analysis (FMEA). Quality Improvement Matrix (QIM) also incorporates the same tools HOQ and FMEA, but QIM also integrates with root cause analysis tool ie five why's. QIM consists of two matrices, In the first matrix aims to identify defects, the root cause of defects and prioritize the root cause of defects. Next, the second matrix searches for and also choose alternative actions for quality improvement. Adaptation of HOQ in this research applied customer requirement from House of Quality that generated to identify defect type that exists at each stage of production. Furthermore, the technical response on House of Quality can degenerate to the root cause of the defect obtained by using the five why's tool and then calculated the strength of the relation between the defect and also the root cause of defect. While the calculation of Risk Priority Number value on FMEA adapted to calculate a value that will be used to prioritize the root cause of defect. This value is obtained from multiplication of severity defect, occurrence root cause of defect, and the relation of the defect with the root cause of defect. The aggregate value of the root cause of defect (ARC) is used to determine the ranking of the root cause of defect priority. The ARC value is derived from the following equation 1 :

$$
A R C_{j}=o_{j} \sum_{i} S_{i} C_{i j}
$$

Where $\mathrm{ARC}_{\mathrm{j}}=$ Aggregate Root Cause of Defect $\mathrm{j}, \mathrm{O}_{\mathrm{j}}=$ The probability of occurrence of the root cause of defect $\mathrm{j}, \mathrm{S}_{\mathrm{i}}=$ Level of the impact of defect $\mathrm{i}$ (Severity), $\mathrm{C}_{\mathrm{ij}}=$ Relation between defect $\mathrm{i}$ with the root cause of defect $\mathrm{j}$. The first matrix can be seen in table 1 below. 
Table 1. Quality Improvement Matrix 1

\begin{tabular}{|c|c|c|c|c|c|c|c|}
\hline \multirow{2}{*}{$\begin{array}{l}\text { Process } \\
\text { Line }\end{array}$} & \multirow[t]{2}{*}{ Defect } & \multicolumn{5}{|c|}{ Root Cause of Defect } & \multirow{2}{*}{$\begin{array}{r}\text { Severity } \\
\text { Defect }\end{array}$} \\
\hline & & $\mathrm{R}_{1}$ & $\mathrm{R}_{2}$ & $\mathrm{R}_{3}$ & $\mathrm{R}_{4}$ & $\mathrm{R}_{5}$ & \\
\hline \multirow[t]{2}{*}{ Process 1} & $\mathrm{D}_{1}$ & $\mathrm{C}_{11}$ & $\mathrm{C}_{12}$ & $\mathrm{C}_{13}$ & & & $\mathrm{~S}_{1}$ \\
\hline & $\mathrm{D}_{2}$ & $\mathrm{C}_{21}$ & $\mathrm{C}_{22}$ & & & & $\mathrm{~S}_{2}$ \\
\hline \multirow[t]{2}{*}{ Process 2} & $\mathrm{D}_{3}$ & $\mathrm{C}_{31}$ & & & & & $\mathrm{~S}_{3}$ \\
\hline & $\mathrm{D}_{4}$ & $\mathrm{C}_{41}$ & & & & & $\mathrm{~S}_{4}$ \\
\hline \multirow[t]{2}{*}{ Process 3} & $\mathrm{D}_{5}$ & & & & & & $\mathrm{~S}_{5}$ \\
\hline & $\mathrm{D}_{6}$ & & & & & & $\mathrm{~S}_{6}$ \\
\hline \multirow[t]{2}{*}{ Process 4} & $\mathrm{D}_{7}$ & & & & & & $\mathrm{~S}_{7}$ \\
\hline & $\mathrm{D}_{8}$ & & & & & & $\mathrm{~S}_{8}$ \\
\hline \multicolumn{2}{|c|}{$\begin{array}{l}\text { Occurrence Root } \\
\text { Cause of Defect }\end{array}$} & $\mathrm{O}_{1}$ & $\mathrm{O}_{2}$ & $\mathrm{O}_{3}$ & $\mathrm{O}_{4}$ & $\mathrm{O}_{5}$ & \\
\hline \multicolumn{2}{|c|}{$\begin{array}{c}\text { Aggregate Root } \\
\text { Cause of Defect } \mathrm{j}\end{array}$} & $\mathrm{ARC}_{1}$ & $\mathrm{ARC}_{2}$ & $\mathrm{ARC}_{3}$ & $\mathrm{ARC}_{4}$ & $\mathrm{ARC}_{5}$ & \\
\hline \multicolumn{2}{|c|}{$\begin{array}{l}\text { Priority Rank Root } \\
\text { Cause of Defect } j\end{array}$} & $\mathrm{PR}_{1}$ & $\mathrm{PR}_{2}$ & $\mathrm{PR}_{3}$ & $\mathrm{PR}_{4}$ & $\mathrm{PR}_{5}$ & \\
\hline
\end{tabular}

Furthermore, the second stage of Quality Improvement Matrix aims to find and also choose the appropriate corrective action to reduce the probability of root cause of defect occurrence impact effectively. The second stage of Quality Improvement Matrix which can be seen in table 2 below.

Table 2. Quality Improvement Matrix 2

\begin{tabular}{|c|c|c|c|c|c|}
\hline \multirow[t]{2}{*}{ Root Cause of Defect } & \multicolumn{4}{|c|}{ Improvement Action $\left(I A_{k}\right)$} & \multirow{2}{*}{$\begin{array}{c}\text { Aggregate } \\
\text { Root Cause of } \\
\text { Defect } \mathrm{j} \\
\end{array}$} \\
\hline & $\mathrm{IA}_{1}$ & $\mathrm{IA}_{2}$ & $\mathrm{IA}_{3}$ & $\mathrm{IA}_{4}$ & \\
\hline $\mathrm{R}_{1}$ & $E_{11}$ & $E_{12}$ & & & $\mathrm{ARC}_{1}$ \\
\hline $\mathrm{R}_{2}$ & $\mathrm{E}_{21}$ & & & & $\mathrm{ARC}_{2}$ \\
\hline $\mathrm{R}_{3}$ & & & & & $\mathrm{ARC}_{3}$ \\
\hline $\mathrm{R}_{4}$ & & & & & $\mathrm{ARC}_{4}$ \\
\hline $\begin{array}{c}\text { Total effectiveness of } \\
\text { action } k\left(T E_{k}\right)\end{array}$ & $\mathrm{TE}_{1}$ & $\mathrm{TE}_{2}$ & $\mathrm{TE}_{3}$ & $\mathrm{TE}_{4}$ & \\
\hline $\begin{array}{l}\text { Degree of difficulty } \\
\text { performing action } \mathrm{k} \\
\left(D_{k}\right)\end{array}$ & $\mathrm{D}_{1}$ & $\mathrm{D}_{2}$ & $\mathrm{D}_{3}$ & $\mathrm{D}_{4}$ & \\
\hline $\begin{array}{c}\text { Effectiveness to } \\
\text { difficulty ratio } \\
\left(E T D_{k}\right) \\
\end{array}$ & $\mathrm{ETD}_{1}$ & $\mathrm{ETD}_{2}$ & $\mathrm{ETD}_{3}$ & $\mathrm{ETD}_{4}$ & \\
\hline Rank of priority $\left(\mathrm{R}_{k}\right)$ & $\mathrm{RP}_{1}$ & $\mathrm{RP}_{2}$ & $\mathrm{RP}_{3}$ & $\mathrm{RP}_{4}$ & \\
\hline
\end{tabular}

$T E_{K}$ value is used to calculate the effectiveness level of each subscription action to be performed to perform the repair process. The $T E_{K}$ value is derived from the sum of the Relation values between the root cause of defect and the proposed improvement action, 
where both are denoted by $\left(E_{j k}\right)$ multiplied by the previously known $\mathrm{ARC}_{j}$ value. So it can be formulated in the following equation 2 ..

$$
T E_{k}=\sum A R C_{j} E_{j k}
$$

Where: $T E_{K}=$ the total effectiveness level of each improvement action, $A R C_{j}=$ Aggregate Root Cause of Defect. $E_{j k}=$ The Relation value of improvement action $\mathrm{k}$ with the root cause of defect.

Once it is known that the $T E_{k}$ value will then be searched for the $D_{k}$ value which is an assessment of the difficulty level in performing the improvement action. The last step is to find the value of $\mathrm{ETD}_{\mathrm{k}}$ that is used to assess the total effectiveness level against the difficulty ratio in doing an improvement action which is further done a ranking by determining the highest to lowest ETD $_{\mathrm{k}}$. This value can be formulated in equation 3 below.

$$
E T D_{k}=\frac{T E_{k}}{D_{k}}
$$

Where $E T D_{k}=$ Total effectiveness level against difficulty ratio in doing improvement action, $T E_{k}=$ the total effectiveness level of each improvement action, $D_{k}=$ value of difficulty level in doing improvement action.

\section{Conclusion}

A new tool for product quality improvement process is proposed by integrating Failure Mode and Effect Analysis (FMEA), House of Quality (HOQ) and also 5 why's namely Quality Improvement Matrix. This proposed tool is developed by following a similar step as HOR. Quality improvement matrix consists of two matrices, the first matrix identify defects and root cause of defects which then prioritize the root cause of defect. In the second matrix improvement strategy or action is formulated and selected. Future work of this research is the application of Quality Improvement Matrix in a case study.

\section{References}

1. Dalgiç, A.C., Vardin, H. and Belibagli, K.B., InTech, (2011)

2. Geramian, A., Mehregan, M.R., Garousi Mokhtarzadeh, N. and Hemmati, M., International Journal of Quality \& Reliability Management, 34, 9 (2017)

3. Gorener, A. and Toker, K., Quality Improvement in Manufacturing Processes to Defective Products using Pareto Analysis and FMEA. 6, 2 (2013)

4. Hagemeyer, C., Gershenson, J.K. and Johnson, D.M., The TQM Magazine, 18, 5 (2006)

5. Kosasih, W., Jurnal Ilmiah Teknik Industri, 3,2 (2015)

6. Liu, H.T., Applied Mathematical Modelling, 35, 1 (2011)

7. Montgomery, D.C., Introduction to statistical quality control (John Wiley \& Sons, New York, 7, 2009)

8. Nyoman Pujawan, I. and Geraldin, L.H., Business Process Management Journal, 15, 6 (2009)

9. Pillay, A. and Wang, J., Reliability Engineering \& System Safety, 79, 1 (2003) 
10. Yang, Q., Yang, S., Qian, Y. and Kraslawski, A., Energy Conversion and Management, 99 (2015) 